\title{
Characterization of a Pterostilbene Dehydrodimer Produced by Laccase of Botrytis cinerea
}

\author{
Anne-Céline Breuil, Philippe Jeandet, Marielle Adrian, \\ Florence Chopin, Nadine Pirio, Philippe Meunier, and Roger Bessis
}

First, third, fourth, and seventh authors: Laboratoire des Sciences de la Vigne, Institut Jules Guyot, Université de Bourgogne, BP 138, 21004 Dijon Cedex, France; second author: Laboratoire d'œnologie, UFR Sciences exactes et naturelles, Moulin de la Housse, BP 1039, 51687 Reims Cedex 2, France; and fifth and sixth authors: Laboratoire de Synthèse et d'Electrosynthèse des Organometalliques, Université de Bourgogne, BP 138, 21004 Dijon Cedex, France.

Accepted for publication 15 December 1998.

\begin{abstract}
Breuil, A.-C., Jeandet, P., Adrian, M., Chopin, F., Pirio, N., Meunier, P., and Bessis, R. 1999. Characterization of a pterostilbene dehydrodimer produced by laccase of Botrytis cinerea. Phytopathology 89:298-302.

In the interaction between grapevines and Botrytis cinerea, one of the main aspects of pathogenicity is fungal ability to degrade phytoalexins synthesized by the plant in response to infection. Laccase-like stilbene oxidase activity in liquid cultures of $B$. cinerea has been shown to be

related to the decrease of phytoalexin concentrations. Recent research and results presented in this paper determined the chemical structure of a pterostilbene metabolite produced by $B$. cinerea. Study of degradation of pterostilbene that has just one free hydroxy phenyl group function allowed us to determine the oxidative dimerization process undergone by grapevine phytoalexins after $B$. cinerea infection. The phytopathological significance of this degradation process in the $B$. cinerea interaction has also been discussed.
\end{abstract}

Grapevines can synthesize antifungal compounds, phytoalexins $(5,9,43)$, in response to elicitation such as an infection by Botrytis cinerea, the causal agent for gray mold $(15,17,23,27)$. Their chemical structure is based on a polyphenol-type stilbene $(14,20)$, resveratrol (trans-3,5,4'-trihydroxystilbene) (23-25) (Fig. 1A). In addition to resveratrol, the family of grapevine phytoalexins covers piceid (resveratrol-3-0 $\beta$-glucopyranose) (46) (Fig. 1B); pterostilbene, a 3,5-dimethylated resveratrol $(8,21,22,24)$ (Fig. 1C); and $\varepsilon$ viniferin, a dehydrodimer of resveratrol $(21,24,25)$ (Fig. 1D). Fungitoxicity of these phytoalexin-type compounds (44) has been defined: $\varepsilon$-viniferin $(21,24)$ and pterostilbene $(22,36)$ have a high fungitoxicity, though resveratrol, the major compound of the grapevine phytoalexin response, has the lowest activity $(1,13,21)$. The phytoalexin response can, therefore, be qualified either by quality parameters with, for example, the response rapidity and the type of synthesized compounds or by quantity with the resveratrol concentration.

In the interaction between grapevines and $B$. cinerea, it is necessary to study the fungal pathogenicity, i.e., its ability to alter the natural resistance put in place by the plant $(15,30,41,42,44)$. Indeed, this fungus has an enzymatic pool able, for example, to lyse cell walls $(38,45)$ or to oxidize polyphenols with an extracellular enzyme, a laccase-like stilbene oxidase $(2,6,29,33)$. Consequently, direct evidence has been obtained that resveratrol and pterostilbene could undergo degradation by this extracellular enzyme produced by B. cinerea (12). Since the first work of Hoos and Blaich (12), much attention has been paid to the biological significance of the laccase-mediated degradation of stilbene phytoalexins, especially in relation to the pathogenicity of $B$. cinerea to grapevines $(18,37,40)$. Recently, we have shown (4) that resveratrol me-

Corresponding author: A.-C. Breuil

E-mail address: sylvain.debord@u-bourgogne.fr

Publication no. P-1999-0208-01R

(C) 1999 The American Phytopathological Society tabolism by laccase includes an oxidative dimerization process leading to a resveratrol dehydrodimer (Fig. 1E), analogous to $\varepsilon$ viniferin produced by grapevines $(25,34)$. Studies, in the same conditions, on degradation of pterostilbene that has one free hydroxy phenyl group became necessary to propose for these stilbenes their site of degradation by $B$. cinerea laccase. Characterization of one pterostilbene metabolite by spectral results and data obtained from nuclear magnetic resonance (NMR) analyses allowed us to understand more about grapevine phytoalexin metabolism by $B$. cinerea and its relation with fungal pathogenicity.

\section{MATERIALS AND METHODS}

Chemicals. trans-Pterostilbene was obtained from R. Pezet and V. Pont (Swiss Federal Agricultural Station of Changins) (35).

Fungal isolates and culture conditions. The strain of $B$. cinerea used in this study (RFA2) was isolated from grapes and obtained from P. Leroux (INRA of Versailles, France).

The strain was cultured on potato dextrose agar (Bio Merieux, Lyon, France) in petri dishes and maintained at $21^{\circ} \mathrm{C}$ with a $12-\mathrm{h}$ light photoperiod. Culture filtrates of $B$. cinerea (37) were obtained by growing the fungus in the medium created by Fournioux and Bessis (7). The medium was distributed into 2-liter Erlenmeyer flasks ( $800 \mathrm{ml}$ per flask) and adjusted to $\mathrm{pH} 5.2$ before inoculation with a conidia suspension (containing about $2 \times 10^{6}$ conidia) obtained as previously described (40). Liquid cultures of $B$. cinerea were incubated for 15 days at $21^{\circ} \mathrm{C}$ on a reciprocal shaker (100 strokes per h) with a 12-h light photoperiod.

Extraction of proteins from culture filtrates of $\boldsymbol{B}$. cinerea. After 15 days of culture, the filtrates were concentrated in vacuo $\left(35^{\circ} \mathrm{C}\right)$, the initial volumes of the filtrates being reduced by $80 \%$. Acetone kept at $-20^{\circ} \mathrm{C}$ was added to the concentrated filtrates in a proportion of $3: 2(\mathrm{vol} / \mathrm{vol})$. A precipitation of extracellular proteins was realized after $1 \mathrm{~h}$ at $4^{\circ} \mathrm{C}$. Centrifugation at $10,000 \times g$ for $20 \mathrm{~min}$ allowed us to obtain a protein pellet that was redissolved in phosphate-citrate buffer $(0.1 \mathrm{M}, \mathrm{pH} 3.4)$ in a proportion of $3 \mathrm{ml}$ of buffer per 2-ml equivalent of concentrated filtrates. 
After centrifugation at $10,000 \times g$ for $10 \mathrm{~min}$, the supernatant containing the protein fraction was kept at $-20^{\circ} \mathrm{C}$ before use.

Incubation of pterostilbene in the presence of culture filtrate proteins of $B$. cinerea and extraction of the pterostilbene metabolite. An ethanolic solution $(2 \mathrm{ml})$ of pterostilbene $(1 \mathrm{mg} / \mathrm{ml})$ was added to $20 \mathrm{ml}$ of the phosphate-citrate buffer containing extracellular proteins of $B$. cinerea $(3.2 \mu \mathrm{g} / \mathrm{ml})$ (3). We verified, using a spectrophotometric test as described by Sbaghi et al. (40), that the laccase-like stilbene oxidase activity was present in purified protein extracts.

Reaction was stopped after $2 \mathrm{~h}$ by extraction using ethyl acetate in a proportion of $1: 1(\mathrm{vol} / \mathrm{vol})$. Organic phases were concentrated under vacuum at $35^{\circ} \mathrm{C}$. The dried extract was then redissolved in absolute ethanol before being analyzed.

Characterization of the pterostilbene metabolite by high performance liquid chromatography (HPLC) analysis coupling photodiode array detection and fluorometry. Analyses using the HPLC method described by Jeandet et al. (16) to identify and quantify grapevine phytoalexins (Vitis spp.) were performed to show pterostilbene degradation after successive times of incubation with protein extracts $(0,30$, and $60 \mathrm{~min})$ and to follow occurrence of its metabolite.

Thin layer chromatography (TLC) semipreparative purification of the pterostilbene metabolite. The pterostilbene metabolite was purified by semipreparative TLC on reversed-phase plates (RP18 F254S; E. Merck AG, Darmstadt, Germany) in methanol/ water $(7: 3, \mathrm{vol} / \mathrm{vol})$. After $3 \mathrm{~h}$ of elution, revelation was obtained under long wavelength UV light $(366 \mathrm{~nm})$. A pterostilbene standard allowed us to identify the nondegraded pterostilbene.
${ }^{\mathbf{1}} \mathrm{H}$ NMR analyses and ${ }^{\mathbf{1}} \mathbf{H}-{ }^{1} \mathbf{H}$ (correlation spectroscopy, COSY) correlations. ${ }^{1} \mathrm{H}(500 \mathrm{MHz})$ spectra and ${ }^{1} \mathrm{H}-{ }^{1} \mathrm{H}(500 \mathrm{MHz})(\mathrm{COSY})$ correlations were recorded on a Brüker DRX 500 spectrophotometer (Brücker S.A., Wissembourg, France). ${ }^{1} \mathrm{H}$ and ${ }^{1} \mathrm{H}-{ }^{1} \mathrm{H}$ NMR chemical shifts $(\delta)$ were reported in parts per million (ppm) relative to $\mathrm{SiMe}_{4}$ as an external reference.

\section{RESULTS AND DISCUSSION}

HPLC analysis coupling photodiode array detection and fluorometry, a useful method for stilbene identification (16), showed that the decrease of pterostilbene concentration was correlated to the appearance and then the rise of a major fluorescent compound (retention time $=24.5 \mathrm{~min}$ ). The UV spectrum of this compound from 200 to $400 \mathrm{~nm}$ showed two bands of absorption maxima, between 315 to $330 \mathrm{~nm}$ and 290 to $310 \mathrm{~nm}$, characteristic of transstilbenes $(10,25)$. These spectral data suggested that this metabolite has kept, at least in part, a trans-stilbenic structure analogous to the compound resulting from resveratrol oxidation by the laccase-like stilbene oxidase of $B$. cinerea $(4,26)$.

Purification of this metabolite for a full characterization was performed by semipreparative TLC on reversed-phased C18; observation under UV light disclosed for this product a blue fluorescence characteristic of trans-stilbenes.

A first analysis by ${ }^{1} \mathrm{H}$ NMR suggested that this compound was a mixture of two isomers: the trans- and the cis-ethylenic isomers. For the trans-ethylenic system, two doublets at the chemical shift $(\delta) 7.0$ (spin-spin coupling constant $[J]=16.5 \mathrm{~Hz})$ and $7.22 \mathrm{ppm}(J=16.5 \mathrm{~Hz})$

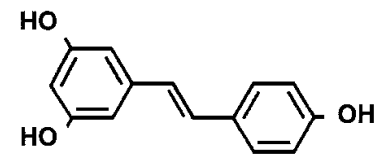

A trans-resveratrol

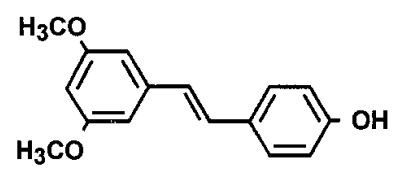

C trans-pterostilbene

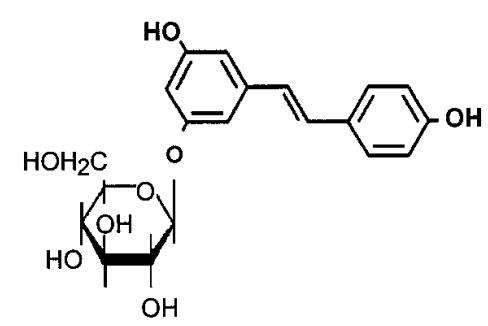

B

Piceid<smiles>Oc1ccc(/C=C/c2cc(O)cc3c2C(c2cc(O)cc(O)c2)C(c2ccc(O)cc2)O3)cc1</smiles>

D $\quad \varepsilon$-viniferin<smiles>Oc1ccc(C=Cc2ccc3c(c2)C(c2cc(O)cc(O)c2)C(c2cc(O)cc(O)c2)O3)cc1</smiles>

\section{E resveratrol trans-dehydrodimer}

Fig. 1. Chemical structures of the grapevine phytoalexin-type compounds A, trans-resveratrol; B, piceid; $\mathbf{C}$, trans-pterostilbene; D, $\varepsilon$-viniferin; and $\mathbf{E}$, resveratrol trans dehydrodimer. 
were observed. The characteristic signals for a cis-ethylenic bond were obtained at $\delta 6.56(J=12.2 \mathrm{~Hz})$ and $6.44 \mathrm{ppm}(J=12.2 \mathrm{~Hz})$. As it is well established that a stilbene can undergo photochemical isomerization $(10,16)$, the pterostilbene metabolite was exposed to UV radiations $\left(366 \mathrm{~nm}\right.$ ) for $30 \mathrm{~min}$. A second ${ }^{1} \mathrm{H}$ NMR analysis then showed that the intensity of signals at $\delta 7.00$ and $7.22 \mathrm{ppm}$ was decreased, whereas the intensity of signals at $\delta 6.56$ and $6.44 \mathrm{ppm}$ increased after UV exposure. This compound has thus undergone a photochemical isomerization that is a typical reaction for trans-stilbenes $(10,16)$. trans-Pterostilbene degradation lead to a major compound that was in the trans-ethylenic form; but its revelation under a 366-nm wavelength used for TLC semipreparative purification resulted in isolation of its two isomeric forms. Characterization of the pterostilbene metabolite was thus achieved with its cis-ethylenic isomer.

Data obtained with the resveratrol metabolite produced by $B$. cinerea laccase under the same conditions (4) and results obtained from high resolution electronic impact mass spectrometry (EIMS) examination (70 eV, M+. calculated 510.20424, M+· found 510.20609, molecular formula $\mathrm{C} 30 \mathrm{H} 32 \mathrm{O} 6$ ) suggested a dehydrodimeric structure for the pterostilbene metabolite, the cis structure presented in Figure 2A (Fig. 2A, protons $[\mathrm{H}]$ and carbon [C] numbers).

To verify this structure (Fig. 2A), detailed comparisons between ${ }^{1} \mathrm{H}$ NMR analysis before and after isomerization and COSY cor-<smiles></smiles>

A pterostilbene cis dehydrodimer<smiles>COc1cc(/C=C(\C)c2ccc3c(c2)C(c2cc(OC)cc(OC)c2)C(c2ccc(O)cc2)O3)cc(OC)c1</smiles>

\section{B pterostilbene trans dehydrodimer}

Fig. 2. A, cis and $\mathbf{B}$, trans chemical structures of the pterostilbene metabolite produced by laccase of Botrytis cinerea. relations $\left({ }^{1} \mathrm{H}-{ }^{1} \mathrm{H}\right)$ were performed. ${ }^{1} \mathrm{H}$ NMR data at $\delta 8.45 \mathrm{ppm}$ showed only one phenolic function. Two groups of two equivalent methoxy functions were determined by ${ }^{1} \mathrm{H}$ NMR analysis at $\delta 3.75$ (singlet, $6 \mathrm{H})$ and $3.65 \mathrm{ppm}$ (singlet, $6 \mathrm{H})$. Protons at $\delta 6.30(\mathrm{~J}=1.84$ and $2.44 \mathrm{~Hz} ; \mathrm{H}-4 \mathrm{E})$ and $6.42 \mathrm{ppm}(J=2.44 \mathrm{~Hz}$; H-4B), whose signals were triplets, showed COSY correlations with protons at $\delta 6.40$ $(J=1.83 \mathrm{~Hz}$; H-2E and H-6E) and $6.36 \mathrm{ppm}(J=2.44 \mathrm{~Hz}$; H-2B and $\mathrm{H}-6 \mathrm{~B}$ ), respectively, whose signals were doublets. Ring (Fig. $2 \mathrm{~A}$, rings $\mathrm{B}$ and $\mathrm{E})$ structure was defined. A proton at $\delta 7.18 \mathrm{ppm}$ $(J=1.83$ and $8.54 \mathrm{~Hz}$; doublet of doublets, H-6D) was correlated with a proton at $\delta 6.82 \mathrm{ppm}(J=7.94 \mathrm{~Hz}$; doublet, H-5D) and with a proton at $\delta 6.96 \mathrm{ppm}$ (broad singlet, H-2D). These results permitted us to confirm ring (Fig. 2A, ring D) structure. Assignments of ring (Fig. 2A, ring A) protons were determined by characteristic chemical shift $(\delta)$ of aromatic protons and their COSY correlations. Two signals corresponding to nonaromatic protons at $\delta 4.48$ $(J=7.93 \mathrm{~Hz} ; \mathrm{H}-2 \mathrm{C})$ and $5.58 \mathrm{ppm}(J=7.93 \mathrm{~Hz} ; \mathrm{H}-1 \mathrm{C})$ showing COSY correlations were assigned to ring (Fig. 2A, ring C) protons.

Data obtained by Hölscher and Schneider (11), Reinero et al. (39), and Breuil et al. (4) added to these results and allowed us to confirm the structure presented in Figure 2A. Proton assignments obtained by NMR analysis are summarized in Table 1.

The trans-metabolite structure was determined by analogy with the cis structure of the pterostilbene metabolite (Fig. 2B).

Degradation of grapevine stilbenes by laccase-like stilbene oxidase of $B$. cinerea thus ended in synthesis of a major compound with a dehydrodimeric structure.

The structure of the pterostilbene metabolite showed that grapevine phytoalexins undergo oxidative dimerization during their metabolism by $B$. cinerea involving the $4^{\prime}$-hydroxyl of the stilbene skeleton. It is well known that laccase, which is a $p$-o-diphenol oxidase (oxygen oxido-reductase, EC 1.10.3.2) synthesized either by plants $(19,31,32)$ or by fungi $(6,29,33)$ provides oxidation of phenol functions situated in a $p$ - $o$-position to give quinonic structures $(31,32)$. We suggest that dimerization of grapevine phytoalexins should have as an intermediate compound a quinone that would lead to a radical cation with a substituted $p$-hydroxy function explaining chemical reactivity of stilbene phytoalexins according to the results obtained by Majima et al. (28). Thus the 4'-hydroxy phenyl group may control metabolism of grapevine phytoalexins by laccase of $B$. cinerea.

From now on, it will be interesting to discuss the biological significance of the laccase-mediated metabolism of phytoalexins in the $B$. cinerea-grapevine interaction.

It has already been reported (40) that pathogenicity of $B$. cinerea isolates to grapevines is strongly associated with their ability to degrade stilbene phytoalexins, though nonpathogenicity seems to be related with an inability to do so. These observations suggest that phytoalexin metabolism by laccase of $B$. cinerea may correspond to a process by which the fungus can escape from the action of the phytoalexin.

Generally, hydroxystilbenes such as resveratrol and their methylated derivatives are scarcely soluble in water. Study of their biological activity requires solubilization through the addition of ethanol at a final concentration of $4 \%(1,36)$. Monomeric stilbenes are relatively more soluble in water than the corresponding dimers.

TABLE 1. Proton assignment determination of the cis structure of the pterostilbene metabolite ${ }^{\mathrm{x}}$

\begin{tabular}{|c|c|c|c|c|c|c|c|c|c|c|c|c|c|c|c|c|}
\hline & \multicolumn{16}{|c|}{ Protons } \\
\hline & $2 \mathrm{C}$ & $1 \mathrm{C}$ & $4 \mathrm{E}$ & $2 \mathrm{~B} 6 \mathrm{~B}$ & $4 \mathrm{~B}$ & $2 \mathrm{E} 6 \mathrm{E}$ & $\mathrm{H}_{\mathrm{a}}$ & $\mathrm{H}_{\mathrm{b}}$ & $5 \mathrm{D}$ & $3 \mathrm{~A} 5 \mathrm{~A}$ & $2 \mathrm{D}$ & $6 \mathrm{D}$ & $2 \mathrm{~A} 6 \mathrm{~A}$ & $\mathrm{OH}(4 \mathrm{~A})$ & $\mathrm{OCH}_{3}$ & $\mathrm{OCH}_{3}$ \\
\hline $\mathrm{d}(\mathrm{ppm})$ & 4.48 & 5.58 & 6.30 & 6.36 & 6.42 & 6.40 & 6.44 & 6.56 & 6.82 & 6.86 & 6.96 & 7.18 & 7.23 & 8.45 & 3.71 & 3.65 \\
\hline$J(\mathrm{~Hz})^{\mathrm{y}}$ & 7.93 & 7.93 & $1.84-2.44$ & 2.44 & 2.44 & 1.83 & 12.20 & 12.20 & 7.94 & 8.55 & & $1.83-8.54$ & 8.55 & & & \\
\hline Signal $^{\mathrm{z}}$ & $\mathrm{d}$ & $\mathrm{d}$ & $\mathrm{t}$ & $\mathrm{d}$ & $\mathrm{t}$ & d & $\mathrm{d}$ & d & d & $\mathrm{d}$ & $\mathrm{s}$ & dd & d & $\mathrm{s}$ & $\mathrm{s}$ & $\mathrm{s}$ \\
\hline
\end{tabular}

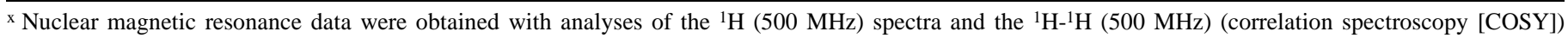
correlations.

y $J=$ spin-spin coupling constant.

${ }^{\mathrm{z}} \mathrm{s}=$ singlet, $\mathrm{d}=$ doublet, $\mathrm{t}=$ triplet, and $\mathrm{dd}=$ doublet of doublets. 
For example, pterostilbene is sparingly soluble in water (ca. $5 \mu \mathrm{g} / \mathrm{ml}$ ), though its condensation product (the dehydrodimer identified in this work) is thoroughly insoluble in water $(<1 \mu \mathrm{g} / \mathrm{ml})$. These values are considerably lower than the concentrations of stilbene phytoalexins required to obtain fungitoxic activity against $B$. cinerea (i.e., ID50 concentrations are 20 and $90 \mu \mathrm{g} / \mathrm{ml}$ for pterostilbene and resveratrol, respectively) $(1,36)$.

Due to this low solubility, it was impossible to determine the biological activity of the pterostilbene dehydrodimer against $B$. cinerea, even when using the practical test described by Adrian et al. (1). In the case of pterostilbene, oxidative dimerization by laccase of $B$. cinerea results in a stilbene of a high molecular weight (twice that of the monomeric form) with four methoxy groups. Thus, metabolism of phytoalexins by $B$. cinerea may appear as an insolubilization of the products formed. The fungus could, therefore, escape from the action of phytoalexins by transformation of these compounds to other products with increasing molecular weight (32) and hydrophobicity. Moreover, in the case of resveratrol, Dercks and Creasy (5) stated that $\varepsilon$-viniferin, a dimeric form of resveratrol analogous to the dimer produced by B. cinerea (4), is less stable (soluble) in water than resveratrol itself, decreasing its biological activity against $B$. cinerea.

These observations reinforce the involvement of the laccase-mediated oxidation of stilbenes in the $B$. cinerea-grapevine interaction.

\section{ACKNOWLEDGMENTS}

This study was supported by grants from Région Bourgogne, Bureau Interprofessionnel des Vins de Bourgogne, and Coopérative Viticole et Agricole de Beaune-Verclum (COPAVIT). We thank J. M. Barbe for recording mass spectra and L. Birden for reviewing the English manuscript. We also thank S. Debord for his technical assistance.

\section{LITERATURE CITED}

1. Adrian, M., Jeandet, P., Veneau, J., Weston, L. A., and Bessis, R. 1997. Biological activity of resveratrol, a stilbenic compound from grapevines, against Botrytis cinerea, the causal agent for gray mold. J. Chem. Ecol. 23:1689-1702.

2. Adrian, M., Rjaei, H., Jeandet, P., Veneau, J., and Bessis, R. 1998. Resveratrol oxidation in Botrytis cinerea conidia. Phytopathology 88:472-476.

3. Bradford, M. M. 1976. A rapid and sensitive method for the quantitation of microgram quantities of protein utilizing the principle of protein-dye binding. Anal. Biochem. 72:248-254.

4. Breuil, A. C., Adrian, M., Pirio, N., Meunier, P., Bessis, R., and Jeandet, P. 1998. Metabolism of stilbene phytoalexins by Botrytis cinerea: 1 . Characterization of a resveratrol dehydrodimer. Tetrahedron Lett. 39: 537-540.

5. Dercks, W., and Creasy, L. L. 1989. The significance of stilbene phytoalexins in the Plasmopara viticola-grapevine interaction. Physiol. Mol. Plant Pathol. 34:189-202.

6. Dubernet, M., Ribereau-Gayon, P., Lerner, H. R., Harel, E., and Mayer, A. 1977. Purification and properties of laccase from Botrytis cinerea. Phytochemistry 16:191-193.

7. Fournioux, J. C., and Bessis, R. 1993. Use of carbon dioxide enrichment to obtain adult morphology of grapevine in vitro. Plant Cell Tissue Organ Cult. 33:51-57.

8. Ghisalberti, E. L., Jefferies, P. R., Lanteri, R., and Matisons, J. 1978. Constituents of propolis. Experientia 34:157-158.

9. Hain, R., Reif, H. J., Krause, E., Langebartels, R., Kindl, H., Vornam, B., Wiese, W., Schmelzer, E., Schreier, P., Stöcker, R., and Stenzel, K. 1993. Disease resistance results from foreign phytoalexin expression in a novel plant. Nature 361:153-156.

10. Hillis, W. E., and Ishikura, N. 1968. The chromatographic and spectral properties of stilbene derivates. J. Chromatogr. 32:323-336.

11. Hölscher, D., and Schneider, R. 1996. A resveratrol dimer from Anigozantos preissii and Musa cavendish. Phytochemistry 43:471-473.

12. Hoos, G., and Blaich, R. 1988. Metabolism of stilbene phytoalexins in grapevines: Oxidation of resveratrol in single-cell cultures. Vitis 27:1-12.

13. Hoos, G., and Blaich, R. 1990. Influence of resveratrol on germination of conidia and mycelial growth of Botrytis cinerea and Phomopsis viticola. J. Phytopathol. 129:102-110.

14. Jagdish Kumar, J., Jyostnaa, D., David Krupadanam, G. L., and Srimannaarayana, G. 1988. Phenanthrene and stilbenes from Pterolo- bium hexapetallum. Phytochemistry 27:3625-3626.

15. Jeandet, P., Bessis, R., Sbaghi, M., and Meunier, P. 1995. Production of the phytoalexin resveratrol by grape as a response to Botrytis attack under natural conditions. J. Phytopathol. 143:135-139.

16. Jeandet, P., Breuil, A. C., Adrian, M., Weston, L. A., Debord, S., Meunier, P., Maume, B., and Bessis, R. 1997. HPLC analysis of grapevine phytoalexins coupling photodiode array detection and fluorometry. Anal. Chem. 69(24):5172-5177.

17. Jeandet, P., Sbaghi, M., and Bessis, R. 1992. The use of phytoalexin induction and of in vitro methods as a tool for screening grapevines for resistance to Botrytis cinerea. Pages 109-112 in: Recent Advances in Botrytis Research. K. Verhoeff, N. E. Malathrakis, and B. Williamson, eds. Pudoc Scientific Publishers, Wageningen, the Netherlands.

18. Jeandet, P., Sbaghi, M., and Bessis, R. 1993. The significance of stilbene-type phytoalexin degradation by culture filtrates of Botrytis cinerea in the vine-Botrytis interaction. Page 84 in: Mechanisms of Plant Defense Responses. B. Fritig and M. Legrand, eds. Kluwer Academic Publishers, Dordrecht, the Netherlands.

19. Joel, D., Marbach, I., and Mayer, A. M. 1978. Laccase in Anacardiaceae. Phytochemistry 17:796-797.

20. Kindl, H. 1985. Biosynthesis of stilbenes. Pages 349-377 in: Biosynthesis and Biodegradation of Wood Components. T. Higuchi, ed. Academic Press, New York.

21. Langcake, P. 1981. Disease resistance of Vitis spp. and the production of the stress metabolites resveratrol, $\varepsilon$-viniferin, $\alpha$-viniferin and pterostilbene. Physiol. Plant Pathol. 18:213-226.

22. Langcake, P., Cornford, C. A., and Pryce, R. J. 1979. Identification of pterostilbene as a phytoalexin from Vitis vinifera leaves. Phytochemistry 18:1025-1027.

23. Langcake, P., and Pryce, R. J. 1976. The production of resveratrol by Vitis vinifera and other members of the Vitaceae as a response to infection or injury. Physiol. Plant Pathol. 9:77-86.

24. Langcake, P., and Pryce, R. J. 1977. A new class of phytoalexins from grapevines. Experientia 33:151-152.

25. Langcake, P., and Pryce, R. J. 1977. The production of resveratrol and the viniferins by grapevines in response to ultraviolet irradiations. Phytochemistry 16:1193-1196.

26. Langcake, P., and Pryce, R. J. 1977. Oxidative dimerization of 4-hydroxystilbenes in vitro: Production of a grapevine phytoalexin mimic. J. Chem. Soc. Chem. Commun. 1412:208-210.

27. Liswidowati, F., Melchior, F., Hohmann, F., Schwer, B., and Kindl, H. 1991. Induction of stilbene synthase by Botrytis cinerea in cultured grapevine cells. Planta 183:307-314.

28. Majima, T., Tojo, S., Ishida, A., and Takamuku, S. 1996. Reactivities of isomerization, oxidation, and dimerization of radical cations of stilbene derivatives. J. Phys. Chem. 100:13615-13623.

29. Marbach, I., Harel, E., and Mayer, A. M. 1984. Molecular properties of extracellular Botrytis cinerea laccase. Phytochemistry 23(12):2713-2717.

30. Mathew, J., Subba Rao, A. V., and Subba Rao, N. V. 1977. Photooxidation of pterostilbene from Pterocarpus marsupuim Roxb. Curr. Sci. 46: 337-338.

31. Mayer, A. M. 1987. Polyphenol oxidases in plants. Recent Progress. Phytochemistry 26(1):11-20.

32. Mayer, A. M., and Harel, E. 1979. Polyphenol oxidases in plants. Phytochemistry 18:193-215.

33. Mayer, A. M., Marbach, I., Marbach, A., and Sharon, A. 1977. Amino acid composition and molecular weight of Botrytis cinerea laccase. Phytochemistry 16:1051-1052.

34. Pedreno, M. A., Morales, M., Calderon, A. A., Zapata, J. M., and Ros Barcalo, A. 1996. A trans-resveratrol oxidizing basic peroxidase isoenzyme from Vitis vinifera. Pages 338-344 in: Plant Peroxidases: Biochemistry and Physiology. C. Obinger, U. Burner, R. Ebermann, C. Penel, and H. Greppin, eds. University of Genova, Genova, Italy.

35. Pezet, R., and Pont, V. 1988. Mise en évidence de ptérostilbène dans les grappes de Vitis vinifera. Plant Physiol. Biochem. 26:603-607.

36. Pezet, R., and Pont, V. 1990. Ultrastructural observations of pterostilbene fungitoxicity in dormant conidia of Botrytis cinerea Pers. J. Phytopathol. 129:19-30.

37. Pezet, R., Pont, V., and Hoang-Van, K. 1991. Evidence for oxidative detoxication of pterostilbene and resveratrol by a lacase-like stilbene oxidase produced by Botrytis cinerea Pers. Physiol. Mol. Plant Pathol. 39:441-450.

38. Reignault, P., Mercier, M., Bompeix, G., and Boccara, M. 1994. Pectin methylesterase from Botrytis cinerea: Physiological, biochemical and immunochemical studies. Microbiology 140:1-7.

39. Reniero, F., Rudolph, M., Angioni, A., Bernreuther, A., Cabras, P., and Mattivi, F. 1996. Identification of two stilbenoids from Vitis roots. Vitis 35(3):125-127.

40. Sbaghi, M., Jeandet, P., Bessis, R., and Leroux, P. 1996. Degradation of stilbene phytoalexins in relation to the pathogenicity of Botrytis cinerea 
to grapevines. Plant Pathol. 45:139-144.

41. Sbaghi, M., Jeandet, P., Faivre, B., Bessis, R., and Fournioux, J. C. 1995. Development of methods using phytoalexin (resveratrol) assessment as a selection criterion to screen grapevine in vitro cultures for resistance to grey mould (Botrytis cinerea). Euphytica 86:41-47.

42. Smith, D. A. 1982. Toxicity of phytoalexins. Pages 218-252 in: Phytoalexins. J. A. Bailey and J. W. Mansfield, eds. Blackie, Glasgow, Scotland.

43. Stoessl, A. 1982 Biosynthesis of phytoalexins. Pages 133-180 in: Phyto- alexins. J. A. Bailey and J. W. Mansfield, eds. Blackie, Glasgow, Scotland.

44. VanEtten, H. D., Matthews, D. E., and Matthews, P. S. 1989. Phytoalexin detoxification: Importance for pathogenicity and practical implications. Annu. Rev. Phytopathol. 27:143-164.

45. Verhoeff, K., Liem, J. I., Scheffer, R. J., and Surya, I. 1983. Cellulolytic activity of Botrytis cinerea in vitro and in vivo. Phytopathol. Z. 106:97-103.

46. Waterhouse, A. L., and Lamuela Raventos, R. M. 1994. The occurence of piceid, a stilbene glucoside in grape berries. Phytochemistry 37:571-573. 